\title{
The quantification of COMT mRNA in post mortem cerebellum tissue: diagnosis, genotype, methylation and expression
} Emma L Dempster*1,2, Jonathan Mill², Ian W Craig² and David A Collier ${ }^{1,2}$

\author{
Address: ${ }^{1}$ Molecular Genetics, Psychological Medicine, Institute of Psychiatry, London, UK and ${ }^{2}$ SGDP Research Centre, Institute of Psychiatry, \\ London, UK \\ Email: Emma L Dempster* - e.dempster@iop.kcl.ac.uk; Jonathan Mill - j.mill@iop.kcl.ac.uk; Ian W Craig - i.craig@iop.kcl.ac.uk; \\ David A Collier - d.collier@iop.kcl.ac.uk \\ * Corresponding author
}

Published: 16 February 2006

BMC Medical Genetics2006, 7:10 doi:10.1 186/1471-2350-7-10
Received: 04 August 2005

Accepted: 16 February 2006

This article is available from: http://www.biomedcentral.com/I47/-2350/7//0

(c) 2006Dempster et al; licensee BioMed Central Ltd.

This is an Open Access article distributed under the terms of the Creative Commons Attribution License (http://creativecommons.org/licenses/by/2.0), which permits unrestricted use, distribution, and reproduction in any medium, provided the original work is properly cited.

\begin{abstract}
Background: The COMT gene is located on chromosome 22qI , a region strongly implicated in the aetiology of several psychiatric disorders, in particular schizophrenia. Previous research has suggested that activity and expression of COMT is altered in schizophrenia, and is mediated by one or more polymorphisms within the gene, including the functional Val158Met polymorphism.
\end{abstract}

Method: In this study we examined the expression levels of COMT mRNA using quantitative RTPCR in 60 post mortem cerebellum samples derived from individuals with schizophrenia, bipolar disorder, depression, and no history of psychopathology. Furthermore, we have examined the methylation status of two $C_{p G}$ sites in the promoter region of the gene.

Results: We found no evidence of altered COMT expression or methylation in any of the psychiatric diagnoses examined. We did, however, find evidence to suggest that genotype is related to COMT gene expression, replicating the findings of two previous studies. Specifically, val ${ }^{158} \mathrm{met}$ ( $r s$ 165688; Val allele) rs737865 (G allele) and rs 165599 (G allele) all showed reduced expression $(P<0.05)$. Finally, we observe a strong sexual dimorphism in COMT expression, with females exhibiting significantly greater levels of COMT mRNA.

Conclusion: The expression of COMT does not appear to be altered in the cerebellum of individuals suffering from schizophrenia, bipolar disorder or depression, but does appear to be influenced by single nucleotide polymorphisms within the gene.

\section{Background}

There has been considerable progress in the search for genes involved in the aetiology of psychiatric disorders such as schizophrenia. Whilst associations have been made between polymorphic variants in various genes (e.g. Neuregulin, Dysbindin, COMT), it is generally not clear whether the associated polymorphisms are the precise functional variants mediating susceptibility [1]. In this study we have examined expression of the Catechol-O-
Methyltransferase (COMT) gene, primarily associated with schizophrenia, but also linked to other forms of psychopathology and variation in normal prefrontal cognitive functioning (see [1-4]). COMT is a widely expressed enzyme that metabolises released dopamine in the synapse. In the prefrontal cortex it is the main component in the dopamine metabolic pathway, since the dopamine transporter is not abundant in this brain region [5-7]. There are two known promoters in COMT that encode 
two different mRNAs, a longer membrane-bound COMT (MB-COMT) and a shorter soluble COMT (S-COMT) [8].

Although COMT, which maps to the velo-cardio-facial syndrome region located at $22 \mathrm{q} 11$, has a well characterised functional mutation that alters enzyme activity (val ${ }^{158} \mathrm{met}$ ) and is responsible for the majority of variation in serum COMT activity levels, it is unclear if this mutation is solely responsible for the association of this gene and schizophrenia. The met ${ }^{158}$ allele has been shown to produce an enzyme with reduced thermostability $[9,10]$, exhibiting about $60 \%$ of the activity of the val ${ }^{158}$ allele in the brain at normal body temperature [11]. The alleles are co-dominant, with heterozygotes exhibiting intermediate activity [12].

Li et al. [13] first found association between schizophrenia and the val ${ }^{158}$ allele, and although there have been some replications $[1,14-16]$ association results with schizophrenia have been inconsistent, and largely negative for depression and bipolar disorder. A recent meta-analysis of the common val ${ }^{158}$ met polymorphism and schizophrenia failed to find overall evidence for a significant association $[17,18]$. Recent focus has thus shifted to haplotype analysis of the COMT gene in schizophrenia. Li et al. [19] examined an extended set of markers in the gene and found strong haplotypic association, which is supported by subsequent haplotype studies by others [20-22]. Population analysis of the previously typed variants showed widely differing allele and haplotype frequencies between populations. It has been postulated that variation in linkage disequilibrium may account for the inconsistencies seen in previous association studies focussing on the $\mathrm{val}^{158} \mathrm{met}$ SNP [23]. It also indicates that either the val ${ }^{158}$ met polymorphism may be a surrogate for a further functional variant involved in the aetiology of schizophrenia, or there are two sites of functional variation in the gene which are relevant to psychosis [19]. Shifman et al. (2002), while finding modest evidence of an association with the val ${ }^{158}$ met SNP, identified significant association between schizophrenia and a COMT haplotype consisting of three SNPs, including val ${ }^{158}$ met, in a large case-control population consisting of Ashkenazi Jews [21]. Functional studies on COMT performed by Bray et al. found that this haplotype is associated with a decrease in COMT mRNA expression [24], an observation that has been replicated by some groups [25], but not by others (e.g. $[11,26])$. Handoko et al. (2005) also found haplotypic association with schizophrenia, with evidence for separate and interacting effects of SNPs in COMT on susceptibility to the disease [20]. The success of haplotype analysis of the gene along with expression work performed by Bray et al. suggests that COMT regulatory regions may be important in schizophrenia, warranting further expression studies of the gene.
It has been recently suggested that epigenetic factors may a key role in the development of schizophrenia [27], and these processes may explain the inconsistent associationstudy results often observed for variants in the COMT gene. Of particular interest is the phenomenon of cytosine methylation at CpG sites, a molecular process that is intrinsically linked to the regulation of gene expression. Methylation at $\mathrm{CpG}$ sites, principally located in CpGislands in the promoter regulatory regions of many genes, disrupts the binding of transcription factors and attracts methyl-binding proteins that are associated with gene silencing and chromatin compaction. Murphy et al. have recently examined the methylation status of six CpG sites in the promoter region of COMT [28]. Using bisulfitegenomic sequencing they found that four of the sites were totally methylated in all individuals assessed, but that two adjacent CpG sites (incorporating cytosines 23 and 27 in their analysis) showed evidence for only partial methylation and some degree of between-individual variation.

In this study we have investigated the role of COMT expression in the development of schizophrenia and two aetiologically-related psychiatric disorders: bipolar affective disorder and depression. We have investigated the relative expression level of COMT in cerebellum tissue obtained from post mortem psychiatric patients. Furthermore, we have correlated gene expression levels with genotype for each of the major candidate susceptibility polymorphisms. Finally, we have accurately quantified the degree of methylation at the two COMT promoter CpG sites to see if epigenetic factors affect gene expression levels and susceptibility to psychopathology.

\section{Methods Samples}

We obtained 60 post mortem cerebellum brain samples from The Stanley Medical Research Institute's brain collection [29]. 15 samples had a diagnosis of schizophrenia, 15 bipolar, 15 depression and 15 controls had no history of mental illness.

\section{Sample preparation}

Both DNA and mRNA were extracted simultaneously using Trizol following the manufacturer's standard protocol (Invitrogen, UK). To ensure no DNA contamination, clean-up of the RNA was performed using QIAGEN spin columns with an additional DNAase step (QIAGEN, Crawley, UK). The quality and purity of total RNA was assayed in a $2 \%$ agarose gel and the recovery was calculated after measuring absorbance with a spectrophotometer at $260 \mathrm{~nm}$. Reverse Transcription was performed using TaqMan reverse transcription reagents with random hexamers (Applied Biosystems, Foster City, USA). All cDNA samples were tested for genomic DNA contamination by 
Table I: Relative expression for gender and the three SNPs analysed using the comparative $\mathbf{C}_{\mathrm{T}}$ method $\left(\Delta \Delta \mathbf{C}_{\mathrm{T}}\right)$.

\begin{tabular}{|c|c|c|c|}
\hline Variable & $\begin{array}{l}\text { Control Group (Relative } \\
\text { expression = I) }\end{array}$ & $\begin{array}{l}\text { Other group (Relative expression compared to } \\
\text { the control group, } \pm \text { SE) }\end{array}$ & \\
\hline Gender & Female & Male & $0.77( \pm 0.07)$ \\
\hline \multirow[t]{2}{*}{ val ${ }^{108 / 158}$ met genotype } & $\mathrm{val} / \mathrm{val}$ & $\mathrm{val} / \mathrm{met}$ & $1.5( \pm 0.11)$ \\
\hline & & met/met & $1.3( \pm 0.09)$ \\
\hline SNP rs_737865 genotype & AA & AG/GG & $0.7( \pm 0.07)$ \\
\hline SNP rs_I 65599 genotype & AA & $A G / G G$ & $0.8( \pm 0.07)$ \\
\hline COMT haplotype (GGG) & Haplotype absent & Putative haplotype carrier & $0.7( \pm 0.06)$ \\
\hline
\end{tabular}

PCR amplification of a non-transcribed sequence. Samples were stored at $-70^{\circ} \mathrm{C}$ prior to further use.

\section{Quantitative PCR}

Quantitative RT-PCR was performed in triplicate for each sample on an ABI Prism 7900HT with TaqMan universal PCR master mix (Applied Biosystems, Foster City, USA) using a standard protocol. An Assay-By-Demand probe/ primer set specific to COMT (Hs00241349_m1), and a $\beta$ Actin housekeeping control gene probe were obtained from Applied Biosystems (Applied Biosystems, Foster City, USA). The expression data produced were analysed and converted into threshold cycle values (Ct-values) using SDS 2.0 (Applied Biosystems, Foster City, USA). The comparative $\mathrm{C}_{\mathrm{T}}$ method $\left(\Delta \Delta \mathrm{C}_{\mathrm{T}}\right)$ was used to measure the relative gene expression. In this method mathematic formulas are used to calculate relative expression levels in comparison to a 'calibrator' (e.g. a different diagnosis group). An arbitrary fluorescence threshold is chosen, based on the variability of the background, and threshold cycle $\left(\mathrm{C}_{\mathrm{T}}\right)$ values are calculated by determining the cycle number at which the fluorescence exceeds this threshold. $\mathrm{C}_{\mathrm{T}}$ values decrease with increasing input target quantity, thus, providing a quantitative measure. The amount of target, normalised to an endogenous housekeeping gene and relative to a calibrator is then given by the formula $2^{-}$ $\Delta \Delta \mathrm{CT}$.

\section{CPG methylation analysis}

Cerebellum DNA was treated with sodium bisulfite using a modified version of the protocol outlined by Olek et al. [30]. Briefly, 800 ng samples of genomic DNA (in a volume of $21 \mu \mathrm{l}$ ) were denatured at $95^{\circ} \mathrm{C}$ for 10 minutes, followed by incubation with $4 \mu \mathrm{l} 2 \mathrm{M} \mathrm{NaOH}$ solution at $50^{\circ} \mathrm{C}$ for 15 minutes. DNA was mixed with $50 \mu \mathrm{l}$ of $2 \%$ low-melting agarose, and $8 \mu$ l beads were formed in prechilled mineral oil. Bisulfite conversion was performed with a $5 \mathrm{M}$ sodium bisulfite solution at $50^{\circ} \mathrm{C}$ for 4 hours, under exclusion of light. The beads were washed twice for 15 minutes in TE buffer $(\mathrm{pH}=8.0)$. Desulfonation was done in $0.2 \mathrm{M} \mathrm{NaOH}$, twice for 15 minutes each, followed by two additional washing steps, again, with TE buffer. Single beads were washed with water and used for subse- quent PCR reactions. Two primers, specific to bisulfitetreated DNA, were designed on the reverse-complement strand to flank the two COMT CpG sites (F: 5'-GAG TAG GTT GTG GAT GGG TTG TA-3' and R: 5'-biotin-ACA TTT CTA AAC CTT ACC CCT CTA-3'). Purification with streptavidin beads and Pyrosequencing ${ }^{\mathrm{TM}}$ (Biotage, Uppsala, Sweden) reactions were performed according to the manufacturer's standard protocol using the sequencing primer 5'-GTA ATA TAG TTG TTA ATA GTA GA-3'.

\section{Genotyping}

Three common COMT SNPs (val ${ }^{158}$ met/rs165688, rs737865, and rs165599) were genotyped using the Amersham SNuPe primer extension assay (GE Healthcare, UK), and products separated on a MegaBACE capillary system (GE Healthcare, UK). Primers and assay conditions are available on request from the authors.

\section{Statistical analysis}

Spearman's rank correlations were calculated for the relationship between COMT expression and all available demographic data to determine if any other factors were contributing to the variation seen in expression. Significant correlations were found with the variables: gender (Rho $=-0.366 \mathrm{P}=0.005)$ and age at death $(\mathrm{Rho}=-0.340$ $\mathrm{P}=0.01)$. To ensure the variation in gender, age and genotype was not confounding the expression differences seen for the different SNP genotypes, ANCOVA was performed with age, gender and genotype as covariates where appropriate. All statistical analyses between groups were performed using SPSS (version 10.0).

\section{Results}

Table 1 describes the expression data observed for COMT. Table 2 describes the association findings. No association was found between disease status and COMT expression $(\mathrm{F}=0.412,3 \mathrm{df}, \mathrm{p}=0.745)$. However, genotype at all three COMT SNPs was found to be associated with gene expression $(\mathrm{p}<0.05)$, with the $\mathrm{G}$ allele of each polymorphism being correlated with decreased expression. Haplotype analysis gave further evidence for an association between COMT genotype and expression with the G-G-G haplotype being significantly correlated with reduced expres- 
Table 2: ANCOVA analysis of COMT gene expression

\begin{tabular}{lccc}
\hline Variable & F & df & Significance P value \\
\hline val158met (rs I65688) (val/val versus val/met and met/met combined) & 5.7 & I & 0.020 \\
rs737865 (AA versus AG and GG) & 5.134 & I & 0.028 \\
rs I65599 (AA versus AG and GG) & 4.18 & 1 & 0.046 \\
COMT haplotype (GGG)* Shifman et al. (2002) "at risk haplotype" & 4.25 & 1 & 0.044 \\
Gender & 5.97 & 1 & 0.018 \\
Diagnosis & 0.412 & 3 & 0.745 \\
\hline
\end{tabular}

sion $(\mathrm{F}=4.25,1 \mathrm{df}, \mathrm{p}=0.04)$. We found some evidence to suggest that COMT is expressed at higher levels in females than males $(\mathrm{F}=5.97,1 \mathrm{df}, \mathrm{p}=0.02)$. Average CpG methylation status across all brain samples were $45.4 \%$ for site 1 (cytosine 27 in the study of Murphy et al. [28]) and $34.5 \%$ for site 2 (cytosine 23). Methylation levels at the two sites were highly correlated $(\mathrm{r}=0.8, \mathrm{p}=<0.000)$. Quantitative measurement of the methylation status of the two promoter CpG sites suggested that there was no association between methylation level and either disease status, or expression level. We did, however, find some preliminary evidence that methylation level was associated with val ${ }^{158}$ met at site 1 (Regression coefficient 0.26; $\left.\mathrm{t}=2.08 ; \mathrm{R}^{2}=0.072 ; P=0.042\right)$, the relationship was dosedependent with val ${ }^{158}$ homozygotes exhibiting lower levels of methlyation at site 1 than met ${ }^{158}$ homozygotes. The same relationship was observed at the second CpG site, although not significant. (Regression coefficient $0.19 ; \mathrm{t}=$ $\left.1.4 ; \mathrm{R}^{2}=0.021 ; P=0.1\right)$.

\section{Discussion}

In this study we have examined the expression of COMT in post mortem cerebellum tissue from individuals diagnosed with schizophrenia, bipolar disorder, and depression. Furthermore, we have examined the role of three polymorphic variants and methylation status at two promoter CpG sites in mediating levels of COMT gene expression. We found no difference in COMT expression or methylation levels in any of the diagnostic groups. However, we found some evidence to suggest that genotype at the three SNP polymorphisms is correlated with expression level in the cerebellum.

We found evidence that the SNPs constituting the Shifman et al. "at risk" schizophrenia haplotype [22] are associated with changes in COMT mRNA expression. This finding is in agreement with those reported by Bray et al. whose data suggest that the specific COMT haplotype implicated in schizophrenia is associated with lower expression of COMT mRNA [24], a finding also replicated by Zhu et al. [25]. Our study is the first positive report that has compared individual genotypes with actual expression levels, as these previous investigations [24,25] both examined relative allele-specific expression in hetero- zygous individuals. It should be noted, however, that there are two non-replications of the original Bray et al. finding. Tunbridge et al. examined mRNA derived from the dorsolateral prefrontal cortex [26]. Using Northern blotting, they were unable to distinguish any differences in expression levels between diagnostic groups, or in the genotypic groups of the val ${ }^{158}$ met SNP. Chen et al. examined COMT expression levels in post mortem prefrontal cortex tissue using real-time quantitative PCR, and also failed to identify any association between any COMT polymorphism and mRNA expression [11]. They did, however, find that the val ${ }^{158}$ met polymorphism significantly affected protein abundance and enzyme activity independently of mRNA expression, confirming the thermolability of the met substitution [11].

A number of factors could explain these inconsistent data. Our study is the only one to examine gene expression in the cerebellum, and it is possible that tissue-specific geneexpression differences exist. Furthermore, gene association studies of COMT in schizophrenia do not ubiquitously support an aetiological role for variants within the gene. It is possible that another functional variant elsewhere in the gene is mediating the putative val ${ }^{158} \mathrm{met}$ association in some populations via linkage disequilibrium (LD). The observation that COMT variants, in particular the val ${ }^{158}$ met SNP, are in strong LD with variants in the nearby $A R V C F$ gene suggest that the alterations in expression associated with particular COMT genotypes seen our data and previous studies by Bray et al. [24] and Zhu et al. [25] may be mediated by variants not yet fully investigated. Further work should examine variants in the VCFS region, in particular the "at risk haplotype" implicated by Sanders et al. that spans the 3'region of COMT and ARVCF [21], to determine if any of these variants could be cis acting factors influencing altered COMT expression, or to substantiate $A R V C F$ as a candidate gene in its own right. Overall, given that the met ${ }^{158}$ allele encodes an enzyme with reduced thermostability, exhibiting about $60 \%$ of the activity of the val ${ }^{158}$ allele [11], and that the observed mRNA expression levels associated with this SNP are not nearly so pronounced, it is likely that this polymorphism does not have a direct effect on transcrip- 
tion through for example altering mRNA stability or transcriptional efficiency.

Interestingly, no association has been identified between COMT expression and disease status in any recent study so far. It has been postulated that schizophrenics may show a decrease in COMT expression [31], paralleling the 22q11 haploinsufficiency seen in individuals with VCFS, who are at greater risk of developing schizophrenia. Overall, the available data suggest there is a haplotype spanning COMT associated with a slightly elevated risk to schizophrenia, which confers a decrease in expression in COMT mRNA. Because of the absence of any noticeable decrease in the schizophrenia diagnostic group, it is probable that this decrease in COMT is only present in a subsection of the schizophrenia patients, and presents only a small but detectable increase in risk of developing the disorder. However the recent finding of a gene-environment effect between COMT val ${ }^{158}$ met and cannabis use in schizophrenia may help to clarify these association findings [32].

It has been widely postulated that conflicting findings in genetic studies of schizophrenia and other complex diseases may be a result of epigenetic factors [33]. In this regard, we decided to investigate the methylation status of two CpG sites in the S promoter region of the COMT gene, first identified by Murphy et al [28]. CpG methylation is a molecular process that is intrinsically linked to the regulation of gene expression. Methylation at $\mathrm{CpG}$ sites, principally located in CpG-islands in the promoter regulatory regions of many genes, disrupts the binding of transcription factors and attracts methyl-binding proteins that are associated with gene silencing and chromatin compaction. Petronis et al. have argued that these epigenetic mechanisms can explain a number of the non-Mendelian features observed in a range of complex psychiatric disorders such as schizophrenia [33]. Unlike DNA sequence variation, which is generally highly stable, epigenetic processes are highly dynamic: they can be tissue-specific, developmentally-regulated, and induced by exposure to a range of environmental stressors. We found that there was no difference in the methylation status of these two CpG sites in any of the diagnostic groups examined. Furthermore, we found no evidence to suggest that methylation of either of these two sites was strongly correlated with COMT expression levels. Interestingly, we did observe a correlation between COMT genotype and methylation levels. Whilst this finding is likely to be a spurious artefact, it is possible that this reflects a difference between the COMT methylation status of each individuals' two chromosomes, potentially indicative of some form of imprinting.
In this regard it is interesting that in contrast to previous studies, we found a significant effect of gender on expression levels, with females exhibiting higher expression of COMT than males. Reasons for this inconsistency between studies could be explained by smaller sample size and the difference in brain region studied. Tunbridge et al. [26] along with Bray et al. [24] both investigated mRNA extracted from prefrontal cortex tissue, raising the possibility that the gender effect is only evident in the cerebellum. There is substantial evidence supporting sexual dimorphism in COMT. Most notably, the G-G-G haplotype association identified by Shifman et al. was principally driven by females [22]. Gogos et al. demonstrated a sexual dimorphism between homozygous COMT deficient mice, with females exhibiting behavioural deficits in anxiety tasks in comparison to males [34], while heterozygous COMT deficient males exhibited increased aggressive behaviour. Furthermore, Karayiorgou et al. found a sexual dimorphic pattern of allele transmission in Obsessive-Compulsive Disorder (OCD) and COMT val ${ }^{158} \mathrm{met}$ polymorphism: males showed a significant association with the met allele, where females showed no association with either allele [35,36]. COMT is involved in the metabolism of catechol-oestrogens [37], which may explain why we observe that the expression level of COMT is elevated in females. The sexual dimorphism of COMT expression, and the possibility of genomic imprinting, is an area that needs further research before any firm conclusions can be made.

The main limitation of this work is the lack of specificity of the COMT probe used to any one form of COMT. MBCOMT is predominantly the form found in brain [38] but how these forms differ in different brain regions to what degree is unknown. Further work should investigate these findings relevant to the two different COMT species.

\section{Conclusion}

To conclude, we have examined the role of COMT expression in the aetiology of schizophrenia, depression, and bipolar disorder. We find no evidence to suggest that COMT expression is altered in any of these forms of psychopathology. Furthermore, we find no difference in COMT promoter methylation patterns in any diagnostic category, and find no evidence to suggest that CpG methylation is directly correlated to gene expression. However, we do find evidence to suggest sexual dimorphism in the expression of the COMT gene, and replicate previous reports implicating polymorphisms in the COMT gene in the regulation of mRNA expression.

\section{Competing interests}

The author(s) declare that they have no competing interests. 


\section{Authors' contributions}

ED performed the majority of the lab-work, data-analysis and drafted the manuscript. JM helped with the expression and $\mathrm{CpG}$ methylation analysis and helped produce the final manuscript. DC and IC participated in the overall design and co-ordination of the study and contributed to the interpretation of findings. All authors read and approved the final manuscript.

\section{Acknowledgements}

This work was supported by a Medical Research Council (UK) PhD studentship to ED.

\section{References}

I. Egan MF, Goldberg TE, Kolachana BS, Callicott JH, Mazzanti CM, Straub RE, Goldman D, Weinberger DR: Effect of COMT Val I 08/ I 58 Met genotype on frontal lobe function and risk for schizophrenia. Proc Natl Acad Sci U S A 200I, 98:6917-6922.

2. Joober R, Gauthier J, Lal S, Bloom D, Lalonde P, Rouleau G, Benkelfat C, Labelle A: Catechol-O-methyltransferase Val-108/I58-Met gene variants associated with performance on the Wisconsin Card Sorting Test. Arch Gen Psychiatry 2002, 59:662-663.

3. Malhotra AK, Kestler LJ, Mazzanti C, Bates JA, Goldberg T, Goldman $D$ : A functional polymorphism in the COMT gene and performance on a test of prefrontal cognition. Am J Psychiatry 2002, 1 59:652-654.

4. Rosa A, Cuesta M, Peralta V, Martinez-Larrea A, Serrano F, Fananas L: New evidence for association between COMT gene and prefrontal neurocognitive functions in schizophrenia. Schizophr Res 2002, 53(Suppl):69.

5. Lewis DA, Melchitzky DS, Sesack SR, Whitehead RE, Auh S, Sampson $A$ : Dopamine transporter immunoreactivity in monkey cerebral cortex: regional, laminar, and ultrastructural localization. J Comp Neurol 2001, 432:1 19-136.

6. Mazei MS, Pluto CP, Kirkbride B, Pehek EA: Effects of catecholamine uptake blockers in the caudate-putamen and subregions of the medial prefrontal cortex of the rat. Brain Res 2002, 936:58-67.

7. Moron JA, Brockington A, Wise RA, Rocha BA, Hope BT: Dopamine uptake through the norepinephrine transporter in brain regions with low levels of the dopamine transporter: evidence from knock-out mouse lines. J Neurosci 2002, 22:389-395.

8. Lotta T, Vidgren J, Tilgmann C, Ulmanen I, Melen K, Julkunen I, Taskinen J: Kinetics of human soluble and membrane-bound catechol O-methyltransferase: a revised mechanism and description of the thermolabile variant of the enzyme. Biochemistry 1995, 34:4202-4210.

9. Lachman HM, Papolos DF, Saito T, Yu YM, Szumlanski CL, Weinshilboum RM: Human catechol-O-methyltransferase pharmacogenetics: description of a functional polymorphism and its potential application to neuropsychiatric disorders. Pharmacogenetics 1996, 6:243-250.

10. Mannisto PT, Kaakkola S: Catechol-O-methyltransferase (COMT): biochemistry, molecular biology, pharmacology, and clinical efficacy of the new selective COMT inhibitors. Pharmacol Rev 1999, 51:593-628.

II. Chen J, Lipska BK, Halim N, Ma QD, Matsumoto M, Melhem S, Kolachana BS, Hyde TM, Herman MM, Apud J, Egan MF, Kleinman JE, Weinberger DR: Functional analysis of genetic variation in catechol-O-methyltransferase (COMT): effects on mRNA, protein, and enzyme activity in postmortem human brain. $\mathrm{Am} J$ Hum Genet 2004, 75:807-82।.

12. Weinshilboum RM, Otterness DM, Szumlanski CL: Methylation pharmacogenetics: catechol O-methyltransferase, thiopurine methyltransferase, and histamine $\mathbf{N}$-methyltransferase. Annu Rev Pharmacol Toxicol 1999, 39:19-52.

13. Li T, Sham PC, Vallada H, Xie T, Tang X, Murray RM, Liu X, Collier DA: Preferential transmission of the high activity allele of COMT in schizophrenia. Psychiatr Genet 1996, 6:131-133.

14. de Chaldee M, Laurent C, Thibaut F, Martinez M, Samolyk D, Petit M, Campion D, Mallet J: Linkage disequilibrium on the COMT gene in French schizophrenics and controls. Am J Med Genet 1999, 88:452-457.

15. Kunugi H, Vallada HP, Sham PC, Hoda F, Arranz MJ, Li T, Nanko S, Murray RM, McGuffin P, Owen M, Gill M, Collier DA: Catechol-Omethyltransferase polymorphisms and schizophrenia: a transmission disequilibrium study in multiply affected families. Psychiatr Genet 1997, 7:97-I0I.

16. Ohmori O, Shinkai T, Kojima H, Terao T, Suzuki T, Mita T, Abe K: Association study of a functional catechol-O-methyltransferase gene polymorphism in Japanese schizophrenics, Neurosci. Lett 1998, 243:109-1 I2.

17. Glatt SJ, Faraone SV, Tsuang MT: Association between a functional catechol O-methyltransferase gene polymorphism and schizophrenia: meta-analysis of case-control and familybased studies. Am / Psychiatry 2003, 160:469-476.

18. Fan JB, Zhang CS, Gu NF, Li XW, Sun WW, Wang HY, Feng GY, Clair $D$ St, He L: Catechol-O-methyltransferase gene Val/Met functional polymorphism and risk of schizophrenia: a large-scale association study plus meta-analysis. Biol Psychiatry 2005, 57:139-144.

19. Li T, Ball D, Zhao J, Murray RM, Liu X, Sham PC, Collier DA: Familybased linkage disequilibrium mapping using SNP marker haplotypes: application to a potential locus for schizophrenia at chromosome 22q I I. Mol Psychiatry 2000, 5:77-84.

20. Handoko HY, Nyholt DR, Hayward NK, Nertney DA, Hannah DE, Windus LC, McCormack CM, Smith HJ, Filippich C, James MR, Mowry $B J$ : Separate and interacting effects within the catechol-Omethyltransferase (COMT) are associated with schizophrenia. Mol Psychiatry 2005, 10:589-597.

2I. Sanders AR, Rusu I, Duan J, Molen JE, Hou C, Schwab SG, Wildenauer DB, Martinez M, Gejman PV: Haplotypic association spanning the 22qII.2I genes COMT and ARVCF with schizophrenia. Mol Psychiatry 2004.

22. Shifman S, Bronstein M, Sternfeld M, Pisante-Shalom A, Lev-Lehman E, Weizman A, Reznik I, Spivak B, Grisaru N, Karp L, Schiffer R, Kotler M, Strous RD, Swartz-Vanetik M, Knobler HY, Shinar E, Beckmann JS, Yakir B, Risch N, Zak NB, Darvasi A: A highly significant association between a COMT haplotype and schizophrenia. Am J Hum Genet 2002, 71:1296-1302.

23. Palmatier MA, Pakstis AJ, Speed W, Paschou P, Goldman D, Odunsi A, Okonofua F, Kajuna S, Karoma N, Kungulilo S, Grigorenko E, Zhukova OV, Bonne-Tamir B, Lu RB, Parnas J, Kidd JR, DeMille MM, Kidd KK: COMT haplotypes suggest $\mathbf{P 2}$ promoter region relevance for schizophrenia. Mol Psychiatry 2004, 9:859-870.

24. Bray NJ, Buckland PR, Williams NM, Williams HJ, Norton N, Owen MJ, O'Donovan MC: A haplotype implicated in schizophrenia susceptibility is associated with reduced COMT expression in human brain. Am J Hum Genet 2003, 73:|52-16I.

25. Zhu G, Lipsky RH, Xu K, Ali S, Hyde T, Kleinman J, Akhtar LA, Mash DC, Goldman D: Differential expression of human COMT alleles in brain and lymphoblasts detected by RT-coupled 5 ' nuclease assay. Psychopharmacology (Berl) 2004, I 177: I 78- 184.

26. Tunbridge E, Burnet PW, Sodhi MS, Harrison PJ: Catechol-o-methyltransferase (COMT) and proline dehydrogenase (PRODH) mRNAs in the dorsolateral prefrontal cortex in schizophrenia, bipolar disorder, and major depression. Synapse 2004, 51:112-118.

27. Petronis A: The origin of schizophrenia: genetic thesis, epigenetic antithesis, and resolving synthesis. Biol Psychiatry 2004, 55:965-970

28. Murphy BC, O'Reilly RL, Singh SM: Site-specific cytosine methylation in S-COMT promoter in $3 I$ brain regions with implications for studies involving schizophrenia. Am J Med Genet $B$ Neuropsychiatr Genet 2005, I 33:37-42.

29. Torrey EF, Webster M, Knable M, Johnston N, Yolken RH: The stanley foundation brain collection and neuropathology consortium. Schizophr Res 2000, 44:15I-I55.

30. Olek A, Oswald J, Walter J: A modified and improved method for bisulphite based cytosine methylation analysis. Nucleic Acids Res 1996, 24:5064-5066.

31. O'Donovan MC, Williams NM, Owen MJ: Recent advances in the genetics of schizophrenia. Hum Mol Genet 2003, I2(Spec 2):RI25-RI33.

32. Caspi A, Moffitt TE, Cannon M, McClay J, Murray R, Harrington H, Taylor A, Arseneault L, Williams B, Braithwaite A, Poulton R, Craig IW: Moderation of the effect of adolescent-onset cannabis 
use on adult psychosis by a functional polymorphism in the catechol-O-methyltransferase gene: longitudinal evidence of a gene $X$ environment interaction. Biol Psychiatry 2005, 57:1117-27.

33. Petronis A: Human morbid genetics revisited: relevance of epigenetics. Trends Genet 200I, 17:| 142-146.

34. Gogos JA, Morgan M, Luine V, Santha M, Ogawa S, Pfaff D, Karayiorgou $M$ : Catechol-O-methyltransferase-deficient mice exhibit sexually dimorphic changes in catecholamine levels and behavior. Proc Natl Acad Sci U S A 1998, 95:9991-9996.

35. Karayiorgou M, Altemus M, Galke BL, Goldman D, Murphy DL, Ott J, Gogos JA: Genotype determining low catechol-O-methyltransferase activity as a risk factor for obsessive-compulsive disorder. Proc Natl Acad Sci U S A 1997, 94:4572-4575.

36. Karayiorgou M, Sobin C, Blundell ML, Galke BL, Malinova L, Goldberg P, Ott J, Gogos JA: Family-based association studies support a sexually dimorphic effect of COMT and MAOA on genetic susceptibility to obsessive-compulsive disorder. Biol Psychiatry 1999, 45:1 178-1189.

37. Creveling CR: The role of catechol-O-methyltransferase in the inactivation of catecholestrogen. Cell Mol Neurobiol 2003, 23:289-291.

38. Matsumoto M, Weickert CS, Beltaifa S, Kolachana B, Chen J, Hyde TM, Herman MM, Weinberger DR, Kleinman JE: Catechol OMethyltransferase (COMT) MRNA Expression in the Dorsolateral Prefrontal Cortex of Patients With Schizophrenia. Neuropsychopharmacology 2003, 28:1521-30.

\section{Pre-publication history}

The pre-publication history for this paper can be accessed here:

http://www.biomedcentral.com/1471-2350/7/10/prepub

Publish with Biomed Central and every scientist can read your work free of charge

"BioMed Central will be the most significant development for disseminating the results of biomedical research in our lifetime. "

Sir Paul Nurse, Cancer Research UK

Your research papers will be:

- available free of charge to the entire biomedical community

- peer reviewed and published immediately upon acceptance

- cited in PubMed and archived on PubMed Central

- yours - you keep the copyright

Submit your manuscript here:

http://www.biomedcentral.com/info/publishing_adv.asp 